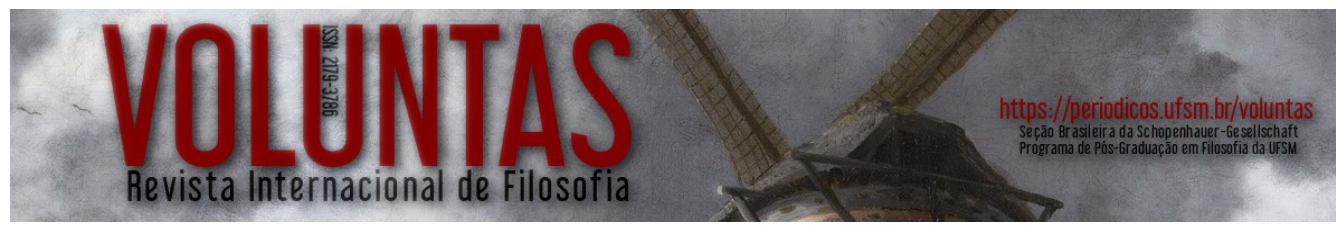

ISSN: 2179-3786

DOI: $10.5902 / 2179378633548$

\title{
A esquerda schopenhaueriana no Brasil
}

\author{
The schopenhauerian left in Brazil
}

\author{
Felipe Durante \\ Doutor em Filosofia pela Universidade Estadual de Campinas (UNICAMP) \\ Professor Substituto da Universidade Federal do Espirito Santo (UFES) \\ E-mail:xfelipedurantex@gmail.com
}

Resumo: Este trabalho tem por objetivo analisar o debate colaborativo estabelecido entre pesquisadores brasileiros sobre a filosofia prática schopenhaueriana. Utilizando as definições de esquerda e direita cunhadas pelo professor Ludger Lütkehaus, apresentaremos e analisaremos os principais aspectos do debate brasileiro no que constitui a sua esquerda schopenhaueriana.

Palavras-chave: Esquerda schopenhaueriana; Ética Prática; Eudemonologia.

Abstract: This article aims to analyze the collaborative debate established among Brazilian researchers on Schopenhauer's practical philosophy. Starting from the definitions created by Professor Ludger Lütkehaus to interpret the Schopenhauer philosophy - the concepts of Schopenhauerian left and right-, we will present and examine the main aspects of the Brazilian debate about the Schopenhauerian left.

Keywords: Schopenhauerian left; Practical ethics; Eudemonology.

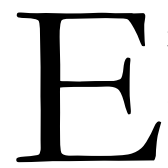

m 1982, o primeiro trabalho acadêmico sobre a filosofia de Arthur Schopenhauer no Brasil, uma dissertação de mestrado intitulado $A$ crítica da razão no pensamento de Schopenhauer sob orientação do professor

Rubens Rodrigues Torres Filho, foi defendido pela professora Maria Lucia Cacciola no departamento de Filosofia da Universidade de São Paulo1. Seu livro Schopenhaner e a questão do dogmatismo ${ }^{2}$, publicado em 1994, logo se tornou leitura obrigatória em língua portuguesa para quem se interessasse pela filosofia do autor no Brasil. A bem cuidada tradução, em 2005, do primeiro tomo da principal obra do filósofo para a língua portuguesa de forma integral, a partir da língua alemã, realizada pelo professor Jair Barboza, facilitou - ou melhor, possibilitou - o acesso daqueles que desejavam se aventurar ou estudar de forma sistemática a filosofia schopenhaueriana. O interesse crescente pela obra do filósofo - tanto pelo público especializado, quanto pelo grande público - incentivou a tradução de outros textos de sua autoria ${ }^{3}$.

\footnotetext{
${ }^{1}$ Cf. CACCIOLA, M.; DEBONA, V.; SALVIANO, J. A bistória e a atual situação dos estudos schopenhauerianos no Brasil, p. 146-150.

2 Cf. CACCIOLA, M. Schopenhauer e a questão do dogmatismo (São Paulo: EDUSP, 1994).

${ }^{3}$ Até o momento nem toda a obra publicada por Schopenhauer possui tradução para o idioma português, e
}

Voluntas: Revista Internacional de Filosofia - periodicos.ufsm.br/voluntas - Santa Maria - Vol. 9, n. 1, jan.-jun. 2018, pp. 137-147 
Em 2004 era criado o Grupo de Trabalho Schopenhauer (GT Schopenhauer) na Associação Nacional de Pós-Graduação em Filosofia (ANPOF) e, em 2005, fundada oficialmente a Seção Brasileira da Schopenhauer-Gesellschaft por ocasião do III Colóquio Internacional Schopenhauer, realizado em São Paulo ${ }^{4}$. Na agenda de eventos realizados no Brasil sobre o filósofo, firmavam-se o bienal Colóquio Internacional Schopenhauer ${ }^{5}$ - o qual conta com a participação predominante das Seções alemã, italiana e japonesa da Sociedade Schopenhauer, bem como de pesquisadores estrangeiros -, o também bienal encontro do GT Schopenhauer durante os Encontros Nacionais da ANPOF, e, regionalmente, os encontros anuais Nietzsche-Schopenhauer do grupo APOENA 6 , em Fortaleza, e o evento anual itinerante nas regiões sul-sudeste Para saber mais Schopenhaner.

Em 2010, um grupo de então pós-graduandos concebeu e efetivou a criação da Revista Voluntas: Estudos sobre Schopenhauer, hoje intitulada Voluntas: Revista Internacional de Filosofia. Esses espaços privilegiados fomentaram as discussões e a aproximação dos estudiosos e interessados na filosofia schopenhaueriana, não apenas entre professoras e professores, mas também entre estudantes de graduação, mestrado e doutorado, nos âmbitos nacional e internacional. Construía-se e consolidava-se no Brasil uma genuína rede de pesquisadores, de debates, e de troca de informações dedicados à filosofia do autor. Professoras, professores, pesquisadoras e pesquisadores da filosofia schopenhaueriana passaram a ocupar papéis de destaque em vários centros universitários espalhados pelo país?

Nesse contexto, publicizaram-se interpretações já existentes - como a de Lütkehaus, a qual, tomando a postura interpretativa assumida em relação ao quietismo (Quietismus), nos aponta uma direita schopenhaueriana, que consistiria na

muitos dos textos traduzidos para o nosso idioma não foram traduzidos de forma integral - sendo lançados parcialmente, por exemplo, os Parerga e Paralipomana e os Dois problemas fundamentais da ética, ou recebendo novos títulos, caso de diversos livros publicados a partir da organização de coletâneas textuais ou de passagens dos manuscritos póstumos schopenhauerianos - ou não foram traduzidos diretamente a partir do idioma alemão. Contudo, os avanços na última década no que se refere a traduções de qualidade - realizadas, em maior parte, por estudiosos acadêmicos da obra do filósofo a partir do idioma alemão - são impressionantes e os prognósticos futuros, animadores.

4 Cf. CACCIOLA, M.; DEBONA, V.; SALVIANO, J. A história e a atual situação dos estudos schopenhauerianos no Brasil, pp. 146-150.

5 A primeira edição do Colóquio foi realizada no ano de 2001, em Curitiba. O evento foi realizado posteriormente nas cidades de Salvador (2003), São Paulo (2005), Rio de Janeiro (2009), Florianópolis (2011), Fortaleza (2013), Salvador (2015). Em 2017 o evento retornou a Curitiba para a sua oitava edição.

${ }^{6}$ As atividades do grupo APOENA podem ser consultadas em http://apoenafilosofia.org/ (Acesso em 10 mar. 2017).

7 Podemos citar como exemplos da disseminação dos estudos sobre Schopenhauer no Brasil (i) a fundação em 2009 na Universidade Estadual de Campinas (UNICAMP) do grupo de pesquisa CriM - Crítica e Modernidade, liderado pelos professores Oswaldo Giacoia Junior (UNICAMP) e Bruno Machado (UFS). O grupo de pesquisa agrega, entre outros interesses, o estudo da filosofia schopenhaueriana, a qual possui uma linha de pesquisa específica: "Schopenhauer: metafísica, estética, ética e política". Cf. dgp.cnpq.br/dgp/espelholinha/ 1186251938377689284330 (Acesso em 10 mar. 2017); (ii) o já mencionado grupo APOENA; (iii) a fundação do Núcleo de Estudos Schopenhauer e Nietzsche da UFRRJ, Cf. http:/ / neschopenhauernietzsche.blogspot.com.br/ (Acesso em 17 fev. 2018); e (iv) o grupo de estudos de filosofia alemã na USP, para ficar apenas em alguns exemplos. 
interpretação canônica, mais disseminada e conhecida, e uma esquerda schopenhaueriana, uma interpretação que acaba por privilegiar as questões sociais, fugindo ao cânone - e emergiram debates sobre aspectos mais específicos, e muitas vezes negligenciados - da filosofia schopenhaueriana, como a sua filosofia prática e aspectos pertencentes ou relacionados a ela, como, por exemplo, a sabedoria de vida ou eudemonologia - presentes em textos como os Aforismos para sabedoria de vida ${ }^{8}$, contido nos Parerga e Paralipomena, e no texto organizado e publicado por Franco Volpi a partir dos manuscritos póstumos do filósofo da vontade sob o título de Die Kunst, Glücklich qu sein ( $A$ arte de ser feli: $)^{9}$.

Um dos debates que vieram à tona nos últimos anos foi justamente aquele acerca do papel e da contradição ou não de uma eudemonologia, de uma sabedoria de vida, de uma filosofia da práxis voltada para a tentativa de tornar a vida o menos infeliz possível, no interior sistemático da obra schopenhaueriana. As interpretações que reconhecem, desenvolvem, problematizam e acentuam a importância dos aspectos da filosofia prática do autor, tais como estas interpretações de cunho eudemonológico, podem ser entendidas como alinhadas a uma interpretação schopenhaueriana à esquerda. Nesse debate, os Aforismos para a sabedoria de vida e a coletânea póstuma organizada por Volpi são centrais.

Nos Aforismos, logo nas primeiras linhas do texto, Schopenhauer explica o sentido pelo qual entende os conceitos de eudemonologia, de sabedoria de vida, bem como a estranheza inicial provocada por um capítulo de sua obra empenhar-se na abordagem do tema. Como é possível notar na citação abaixo, os termos assumem significado um tanto diverso do utilizado correntemente:

Tomo aqui o conceito de sabedoria de vida num sentido totalmente imanente, a saber, o da arte de conduzir a vida da maneira mais agradável e feliz possível, cuja instrução também poderia ser chamada de eudemonologia: ela seria, por conseguinte, a indicação para uma existência feliz ${ }^{10}$.

É bom recordar que existência feliz. (glückliches Daseyn), para o filósofo, é um mero eufemismo, algo que não existe, uma contradição ${ }^{11}$, sendo o máximo alcançável frente

\footnotetext{
${ }^{8}$ Para uma leitura cotejada e citações, utilizamos a edição traduzida por Gabriel Valladão (SCHOPENHAUER, A. Aforismos para a sabedoria de vida. Trad. Gabriel Valladão Silva. Porto Alegre: L\&PM, 2014).

${ }^{9}$ Cf. SCHOPENHAUER, A. A arte de ser feliz. Org. de Franco Volpi; tradução de Eduardo Brandão. São Paulo: Martins Fontes, 2008.

10 SCHOPENHAUER, Aforismos para a sabedoria de vida, p. 7; PP, IV p. 347. No original alemão: „Ich nehme den Begriff der Lebensweisheit hier gänzlich im immanenten Sinne, nämlich in dem der Kunst, das Leben möglichst angenehm und glücklich durchzuführen, die Anleitung zu welcher auch Eudämonologie genannt werden könnte: sie wäre demnach die Anweisung zu einem glücklichen Daseyn“.

11 “Antes, verifica-se uma completa contradição em querer viver sem sofrer, contradição que também se anuncia com frequência na expressão corrente "vida feliz" (SCHOPENHAUER, A. WWV I, \16, p. 108; MVR I, \ 16, p. 147. No original alemão: „Es liegt vielmehr ein vollkommener Widerspruch darin, leben zu wollen ohne zu leiden, welchen daher auch das oft gebrauchte Wort »säliges Leben« in sich trägt“".
} 
às dores e aos sofrimentos do mundo uma vida heroica (heroischer Lebenslauf) ${ }^{12}$. É nesse sentido que ele emprega o termo "vida feliz" (glückliches Leben) ${ }^{13}$. O mais próximo do que poderia ser chamado de vida feliz, que consistiria em conduzir a vida da forma menos infeliz possível, ocorre "quando desejo e satisfação se alternam em intervalos não muito curtos nem muito longos, o sofrimento ocasionado por eles é diminuído ao mais baixo grau, fazendo o decurso de vida o mais feliz possível"14.

Além disso, Schopenhauer admite uma certa contradição no estudo de uma eudemonologia, de uma sabedoria de vida, na busca da vida menos infeliz possível, caso não se atente para algumas ressalvas:

\begin{abstract}
Desse conceito de existência segue que nos apegaríamos a ela por ela mesma, e não meramente por medo da morte; e disto, por sua vez, que gostaríamos de vê-la durar infinitamente. Agora, se a vida humana corresponde ao conceito de tal existência, ou se sequer pode corresponder-lhe, é uma questão conhecidamente negada por minha filosofia, enquanto que a eudemonologia pressupõe sua afirmação. Isso porque ela repousa sobre o equívoco inato cuja refutação abre o quadragésimo nono capítulo do segundo volume de minha obra principal. Para, apesar disso, poder ainda elaborar uma eudemonologia, tive, pois, de me desviar completamente do ponto de vista metafísico-ético mais elevado ao qual a minha filosofia propriamente dita conduz. Por consequência, toda a discussão que aqui será feita repousa em certa medida sobre uma acomodação, a saber, na medida em que permanece no ponto de vista empírico comum, atendo-se a seu equívoco ${ }^{15}$.
\end{abstract}

A passagem supracitada mobiliza elementos decisivos para a justificativa da escrita de um texto que tenha como finalidade a sabedoria de vida, e elementos para a justificativa de uma leitura da filosofia schopenhaueriana à esquerda. Em primeiro

\footnotetext{
12 "Uma vida feliz é impossível: o máximo que uma pessoa pode atingir é um curso de vida beroico" (SCHOPENHAUER, A. PP, \172a, V, p. 349; PP \172a, p. 185), tradução ligeiramente alterada. No original alemão: „Ein glückliches Leben ist unmöglich: das höchste, was der Mensch erlangen kann, ist ein heroischer Lebenslauf“".

13 Apesar da utilização do termo vida feliz, é importante notar que Schopenhauer não toma estritamente o conceito tal qual sua significação estoica. Sobre a forma pela qual Schopenhauer assimila e interpreta a filosofia estoica, Cf. DEBONA, V. Schopenhaner e as formas da razão - O teórico, o prático e o ético-mistico; CHEVITARESE, L. Schopenhauer e o estoicismo; VIESENTEINER, J. "Prudentia" e o uso prático da razão em Schopenhauer.

${ }^{14}$ SCHOPENHAUER, A. WWV I, \57, p. 370; MVR I, \57, p. 404. No original em alemão: „Daß Wunsch und Befriedigung sich ohne zu kurze und ohne zu lange Zwischenräume folgen, verkleinert das Leiden, welches Beide geben, zum geringsten Maßße und macht den glücklichsten Lebenslauf aus“.

${ }^{15}$ SCHOPENHAUER, A. Aforismos para a sabedoria de vida, p. 7; PP, IV p. 347, tradução ligeiramente alterada. No original alemão: „Aus diesem Begriffe desselben folgt, daß wir daran hiengen, seiner selbst wegen, nicht aber bloß aus Furcht vor dem Tode; und hieraus wieder, daß wir es von endloser Dauer sehn möchten. Ob nun das menschliche Leben dem Begriff eines solchen Daseyns entspreche, oder auch nur entsprechen könne, ist eine Frage, welche bekanntlich meine Philosophie verneint; während die Eudämonologie die Bejahung derselben voraussetzt. Diese nämlich beruht eben auf dem angeborenen Irrthum, dessen Rüge das 49. Kapitel im 2. Bande meines Hauptwerks eröffnet. Um eine solche dennoch ausarbeiten zu können, habe ich daher gänzlich abgehn müssen von dem höheren, metaphysisch-ethischen Standpunkte, zu welchem meine eigentliche Philosophie hinleitet. Folglich beruht die ganze hier zu gebende Auseinandersetzung gewissermaaßen auf einer Ackommodation, sofern sie nämlich auf dem gewöhnlichen empirischen Standpunkte bleibt und dessen Irrthum festhält“.
}

Voluntas: Revista Internacional de Filosofia - periodicos.ufsm.br/voluntas - Santa Maria - Vol. 9, n. 1, jan.-jun. 2018, pp. 137-147 
lugar, ela afirma que uma sabedoria de vida se funda em uma torção do conceito de existência, como se a existência fosse desejada. Em segundo lugar, uma eudemonologia estaria situada no âmbito da afirmação da vontade, o que o autor admite não ser o expediente mais adequado, dado que isso se configura quase como uma contradição em relação ao que enuncia sua própria filosofia. Por fim, ele reconhece uma mudança do âmbito, da perspectiva na qual se assenta a discussão: não mais na chave de uma ética-metafísica, mas de uma ética-empírica. Essa alteração de perspectiva é chamada por ele de desvio (abgehen) ${ }^{16}$, de acomodação (Akkommodation), visando o afastamento da contradição que seria tratar a questão envolvida em um âmbito ético-metafísico.

Tal contradição consistiria no fato de, após averiguar e explicitar em outras obras os problemas decorrentes da afirmação da vontade e da sua impossibilidade e limitação de se constituir como a solução para os sofrimentos do mundo, e de constatar, por outro lado, que a negação da vontade seria a via de supressão dos sofrimentos, Schopenhauer insistir na primeira como possibilidade de resolução dos problemas mais centrais de sua filosofia. A contradição é evitada de modo muito sutil, através de um desvio, de uma acomodação, de uma mudança de perspectiva na consideração da questão.

Essa mudança de perspectiva, para ser entendida de forma a dissolver a contradição possível, envolve a adesão a algumas formas de interpretação da filosofia do autor. O professor Leandro Chevitarese, em sua tese de doutoramento, foi um dos pioneiros na abordagem da questão no Brasil ${ }^{17}$, reflexão que levou para outros de seus textos. Tomando como ponto de partida uma passagem do livro de Safranski "supondo que a vida valha a pena ser vivida, como então deveríamos conduzi-la de tal modo a obter a melhor medida de felicidade alcançável?"18 -, a qual ele considera a pergunta norteadora dos Aforismos e a base de uma ética do "como se" (Als-ob), o professor estabelece quatro sentidos para que seja possível entender a mudança de perspectiva operada nessa obra, tornando-a possível de ser escrita:

\footnotetext{
$16 \mathrm{O}$ verbo utilizado em alemão, abgehen, pode ser traduzido, também, por desprender-se, afastar-se, deixar. Fica marcado, assim, o sentido de afastamento da forma até então utilizada no desenvolvimento da argumentação de outras obras e a mudança de perspectiva.

${ }^{17}$ Cf. CHEVITARESE, L. A ética em Schopenhauer: que "liberdade nos resta" para a prática de vida?

${ }^{18}$ SAFRANSKI, R. Schopenhaner e os anos mais selvagens da filosofia: uma biografia, p. 621.
} 
1) Façamos como se a vida valesse a pena ser vivida e nos empenhemos na "arte de conduzir a vida do modo mais agradável e feliz possível" - neste primeiro sentido, o "como se" aplica-se à própria vida e à possibilidade da felicidade; 2) Passemos a agir como se a nossa própria conduta fosse um efeito absoluto de nosso pensamento, ou seja, como se pudéssemos agir de modo diferente do que somos - neste segundo sentido, o "como se" aplica-se à nossa conduta; 3) Continuemos a viver como se os males desnecessários jamais nos aconteçam e os inevitáveis venham sempre a tardar - neste terceiro sentido, o "como se" refere-se ao curso dos acontecimentos da vida; 4) Enfrentemos a vida de maneira positiva como se não estivéssemos entregues à inexorabilidade de tudo que acontece, como se não houvesse um destino - neste quarto sentido, o "como se" faz referência à problemática da necessidade. Portanto, a "ética do como se" aplica-se à vida, à conduta, aos acontecimentos desagradáveis e ao destino $^{19}$.

O "como se" seria a tradução do que Schopenhauer chama de acomodação, desvio, ou afastamento, i.e., o "como se" seria a explicação e a significação da mudança de perspectiva, do plano ético-metafísico para o plano ético-empírico, que possibilita o desenvolvimento de uma eudemonologia dentro do sistema filosófico schopenhaueriano.

Chevitarese, então, assimila a tese do professor Thomas Brum de que a proposta eudemonológica consistiria em uma "espécie de sabedoria teatral"20. Essa consistiria em uma metáfora que explica o modus operandi da eudemonologia:

[...] a própria vida poderia ser compreendida como um grandioso espetáculo teatral, o teatro da vontade: personagens diferentes, em variados cenários, interpretando o mesmo drama, a tragédia da vontade. Conquistar a "sabedoria teatral" significa ser um bom ator do papel que lhe cabe ${ }^{21}$.

Assim, ele toma a ética do como se e a sabedoria teatral como bases hermenêuticas para compreender e explicar como a sabedoria de vida, como a eudemonologia schopenhaueriana, são possíveis. O "como se" como justificativa da mudança de perspectiva; a sabedoria teatral como finalidade mais bem executada da eudemonologia.

A grande parte dos pesquisadores e comentadores que se debruçam sobre a questão acabam por reconhecer a mudança de perspectiva como questão chave para compreensão e justificativa da presença de um capítulo da obra do "filósofo do pessimismo" que verse sobre eudemonologia, afinal, como nos adverte Volpi, "[...] ninguém iria querer aprender felicidade com um professor de pessimismo" 22 .

\footnotetext{
${ }^{19}$ CHEVITARESE, L. Schopenhauer e o estoicismo, p. 170.

${ }^{20}$ BRUM, J. O pessimismo e suas vontades: Schopenhauer e Nietzsche, p. 51.

${ }^{21}$ CHEVITAERESE, L. Schopenhauer e o estoicismo, p. 170.

22 VOLPI, F. Apresentação. In: SCHOPENHAUER, A. A arte de ser feliz, p. VIII.
} 
Nota-se, contudo, o emprego de diferentes nomenclaturas para esse mesmo movimento textual 23 .

O professor Jorge Luiz Viesenteiner localiza a mudança de perspectiva, essa acomodação, na passagem de um ponto de vista superior, ético-metafísico para o que ele denomina de grande pessimismo ${ }^{24}$ :

[...] Schopenhauer também executa a trajetória que vai de um "ponto de vista superior, ético-metafísico", típico do pessimismo de $O$ mundo, para aquilo que denominamos de 'grande pessimismo', i.é., uma "acomodação" na vida que faz o autor se distanciar de um pessimismo absoluto, para vislumbrar as possibilidades de 'viver menos infeliz'. O 'grande pessimismo' é a prerrogativa daquele que agora pode executar em si as possibilidades de uma vida 'menos infeliz', somente porque vivenciou até a medula o próprio pessimismo, ou se quisermos, um 'otimismo prático' que é o privilégio daquele que foi suficientemente pessimista, experimentando cada um dos seus padecimentos na própria carne ${ }^{25}$.

E completa, explicando o que deve ser entendido por "grande pessimismo":

[...] 'grande pessimismo' não consiste mais nas hipóteses de negação do querer viver, mas no distanciamento do mundo e dos outros, voltando-se para si mesmo a fim de esboçar as possibilidades de uma vida 'menos infeliz'26.

O professor e tradutor Jair Barboza define o pensamento de Schopenhauer como pendular, um pensamento que oscila entre pessimismo metafísico e otimismo prático ${ }^{27}$, no qual o íntimo de cada um é caracterizado pelo sofrimento, mas no qual também é possível atingir uma certa espécie de felicidade limitada, ainda mais se o sujeito for guiado por uma sabedoria de vida ${ }^{28}$. Talvez a imagem não seja a mais acertada para explicar o movimento textual realizado pelo filósofo, dado que não é operada uma oscilação de um âmbito ao outro: tem-se marcadamente duas perspectivas de análise que se suplementam, que coexistem, mas que não são totalmente codependentes, e nas quais, durante a exposição, o filósofo não alterna de registro. Quando o discurso está situado no âmbito ético-metafísico a argumentação desenvolve-se nele; quando adentramos a eudemonologia, adentramos um outro registro, um outro âmbito, uma outra perspectiva da argumentação que se assenta sobre uma acomodação, como visto, de forma a evitar

\footnotetext{
${ }^{23}$ Os termos empregados para designar essa duplicidade de perspectivas podem variar entre, de um lado, éticometafísico, metafísica dos costumes, Ética da compaixão, Pessimismo metafísico, Grande Ética, em contraposição a termos como ético-empírico, ético-eudemonológico, grande pessimismo, otimismo prático, Pequena Ética.

${ }^{24}$ Cf. VIESENTEINER, J. L. "Prudentia" e o uso prático da razão em Schopenhauer, p. 9.

25 Ibidem.

${ }^{26}$ Ibidem.

${ }^{27}$ Cf. BARBOZA, J. Schopenhauer, p. 53.

${ }^{28}$ BARBOZA, J. Em favor de uma boa qualidade de vida. In: SCHOPENHAUER, A. Aforismos para a sabedoria de vida, p. XIII.
} 
a contradição que o próprio autor nota e da qual nos adverte no início dos Aforismos. O termo "otimismo prático" também seria muito forte para o contexto; "pessimismo pragmático", talvez, seja mais adequado, uma vez que não se trataria de uma disposição em ver as coisas da vida pelo lado bom e positivo, esperando uma solução sempre favorável para as intempéries do mundo, mas, antes, de reduzir os danos da existência. Reduzir os danos da existência deve ser entendido, aqui, como o controle dos efeitos de um problema sem que com isso se elimine as suas causas, dado que não é possível extirpar a essência do mundo ou mudar o que os indivíduos são - o que nos parece estar perfeitamente de acordo com a proposta dos Aforismos e da eudemonologia schopenhauerianos.

A tese de doutoramento de Vilmar Debona, A outra face do pessimismo: entre radicalidade ascética e sabedoria de vida ${ }^{29}$, tem, dentre tantos, o mérito de esmiuçar essa questão. Debona diferencia dois âmbitos, duas perspectivas da filosofia schopenhaueriana, as quais ele denomina Grande Ética e Pequena Ética - e aqui, justiça seja feita, Debona defende a existência de uma ética da melhoria que não necessariamente dependa da sabedoria de vida, mas que se coloca em sintonia com ela.

A Grande Ética seria o âmbito da ética da compaixão, do ascetismo, da metafísica dos costumes, dos assuntos comumente tratados pelo cânone schopenhaueriano e pelas interpretações ditas de direita de sua filosofia; a Pequena Ética seria referida à sabedoria de vida e à vida prudente no mundo através de uma ética da melhoria, não englobando a questão das virtudes, da moralidade, sendo restrita à legalidade das ações. Na letra do comentador, podemos ler:

Este pessimismo pragmático pode ser tomado em paralelo com algumas formulações específicas do âmbito da sabedoria de vida, mas também com alguns contextos e formulações da fundamentação da moral. Estes últimos aparecem, por exemplo, como "ética da melhoria" (bessernde Ethik) e como moral do "como se" $(A l s-O b)$. O conjunto destas formulações, principalmente por não participar da moral propriamente dita (pois pertence ao âmbito eudemonológico ou empírico), pode ser chamado de pequena ética, critério a partir do qual seria possível diferenciá-la em relação à autêntica moralidade metafísica e ao ascetismo místico, que aqui denomino de grande ética [...]. A hipótese desta divisão entre grande e pequena ética não é pensada a partir da conhecida classificação das obras aristotélicas ou de outras conceituações da história da Filosofia, mas pode ser captada a partir daquele mesmo parâmetro (ofertado pelo próprio Schopenhauer) que serve para o caso do pessimismo pragmático, ou seja, na esteira do próprio "desvio" da metafisica na medida em que o ponto de vista ético-metafisico é considerado como um "ponto de vista superior". Isto é, pelo fato de a filosofia schopenhaueriana considerar [...] a esfera ético-metafisica como a perspectiva "mais elevada", então ela poderia ser chamada também, em algum sentido, de "grande perspectiva". Nesse caso,

\footnotetext{
${ }^{29}$ Cf. DEBONA, V. A outra face do pessimismo: entre radicalidade ascética e sabedoria de vida.
} 
a perspectiva oriunda do desvio deste patamar superior, horizonte no qual repousa uma acomodação ou adaptação ao princípio de autoconservação (assim como ao principium individuationis), no qual se "permanece preso ao ponto de vista comum, empírico", representaria um grau "menos elevado", ou inferior, da ética. Destaco, então, que embora Schopenhauer não tenha usado as expressões grosse Ethik e kleine Ethik para apresentar sua doutrina moral, o farei aqui a partir do pressuposto interpretativo acima indicado ${ }^{30}$.

Assim, ainda segundo Debona, a fundamentação ética do agir, e a sua significação íntima seriam objetos de escrutínio da Grande Ética; o agir mediato, direcionado, e refletido diriam respeito à esfera da Pequena Ética ${ }^{31}$. Em algumas partes de seu texto, Debona toma como sinônimos a Pequena Ética e uma Ética Sugestiva:

Schopenhauer, nesse sentido, não teria apenas demonstrado as
contradições intrínsecas a uma ética prescritiva, tal como elaborada por Kant,
e, em lugar dela, insistido na pertinência de uma ética descritiva. Em paralelo
a esta última - e, inicialmente, com o mesmo método descritivo - o
pensador teria indicado também uma espécie de "ética sugestiva". A ética da
compaixão detém-se em descrever os casos em que, misteriosamente, uma
motivação apresenta-se suficientemente forte para originar uma ação
altruísta. Já a mencionada dimensão sugestiva da ética, isto e, à pequena
ética, caberia a função de indicar ao indivíduo - apoiando-se no estrato
cognitivo do intelecto - que, por exemplo, um caráter naturalmente
egoísta não necessariamente produzirá sempre ações misantrópicas; que um
caráter cujas ações tendem a ser motivadas pela maldade, não
necessariamente se tornará um serial killer, ou mesmo que um caráter mais
receptivo a motivações compassivas nem sempre produzirá ações
filantrópicas. Seja qual for a índole íntima, as máximas de sabedoria de
vida e as próprias experiências colhidas do "histórico do caráter"
permitiriam a exposição de cada uma dessas personalidades inatas as
circunstâncias variegadas - e até mesmo opostas - em relação aquelas as
quais elas tendem naturalmente ${ }^{22}$.

Nota-se que os comentadores mobilizam, cada um a seu modo, elementos e conceitos para dar conta de explicar e justificar uma sabedoria de vida no interior da obra schopenhaueriana, como ela se configura, a sua finalidade, bem como a forma pela qual ela pode se realizar sem realmente constituir uma contradição com a filosofia do autor. Todos concordam que existe uma diferenciação de perspectivas nas quais a eudemonologia, a sabedoria de vida, é desenvolvida - seja ela uma acomodação, um desvio, um afastamento, ou uma cisão - e que a eudemonologia serve como uma espécie de guia para diminuição dos sofrimentos na vida prática empírica.

Nesse viés hermenêutico, nota-se a função central exercida pelo caráter adquirido e pelo intelecto. É o caráter adquirido que possibilita o melhor conhecimento de si no mundo, fornecendo motivos e contramotivos que, através do intelecto, podem

\footnotetext{
${ }^{30}$ Idem, p. 197-198.

31 Idem, p. 199.

32 Idem, p. 202.
} 
sugestionar a vontade em agir da forma mais adequada ao caráter do indivíduo e, consequentemente, auxiliá-lo no experienciar a vida do modo menos infeliz possível, evitando ao máximo os tormentos que são desnecessários, diminuindo aqueles que são inevitáveis, buscando a sua atmosfera mais adequada (angemesse Atmosphäre), e fazendo, em uma situação ideal, "o que nos é possível nos limites do que nos é inevitável"33. O caráter adquirido permite a ampliação da constelação de motivos do indivíduo - os próprios Aforismos, a educação e o código penal podem ser entendidos assim: o primeiro e o segundo como um elenco de motivos que possuem a finalidade de auxiliar o indivíduo a viver de forma prudente; o último, uma lista de contramotivos, como tentativa de evitar ações consideradas ilegais.

O debate filosófico brasileiro pôde, a partir de um genuíno e intenso diálogo de cooperação com centros de excelência internacionais, explorar e desenvolver teses sobre a interpretação da filosofia schopenhaueriana de forma original, abrindo novos horizontes de pesquisa e reflexão. Abriram-se e aprofundaram-se perspectivas de trabalho e reflexão sobre a filosofia do autor e sua atualidade no âmbito éticoempírico, da filosofia social, da filosofia prática, espaço tido como menos importante e comumente renegado. Os resultados desse debate começam a surgir na forma de artigos, iniciações científicas, dissertações de mestrado, e teses de doutorado. Esse artigo é uma tentativa de homenagem e de agradecimento a todas e todos os envolvidos nesse processo.

\section{Referências bibliográficas}

BARBOZA, J. Schopenhauer. Rio de Janeiro: Jorge Zahar Ed., 2003.

BRUM, J. O pessimismo e suas vontades: Schopenhauer e Nietzsche. Rio de Janeiro: Rocco, 1998.

CACCIOLA, M. Schopenhaner e a questão do dogmatismo. São Paulo: EDUSP, 1994.

CACCIOLA, M.; DEBONA, V.; SALVIANO, J. A história e a atual situação dos estudos schopenhauerianos no Brasil. Voluntas: Estudos sobre Schopenhauer, v. 4, n.1, pp. 146-150, 2013.

CHEVITARESE, L. A ética em Schopenhauer: que "liberdade nos resta" para a prática de vida? Tese (Doutorado em Filosofia). Pontifícia Universidade Católica do Rio de Janeiro, Rio de Janeiro, 2005.

CHEVITARESE, L. Schopenhauer e o estoicismo. Ethic@ - Revista Internacional de Filosofia Moral, Florianópolis, vol. 11, n. 2, 2012.

\footnotetext{
${ }^{33}$ Idem, p. 120.
} 
DEBONA, V. Schopenhaner e as formas da razãa - O teórico, o prático e o ético-místico. São Paulo: Annablume, 2010.

DEBONA, V. A outra face do pessimismo: entre radicalidade ascética e sabedoria de vida. Tese (Doutorado em Filosofia). Universidade de São Paulo, São Paulo, 2013.

SAFRANSKI, R. Schopenhauer e os anos mais selvagens da filosofia: uma biografia. Tradução de Willian Lagos. São Paulo: Geração Editorial, 2011.

SCHOPENHAUER, A. Arthur Schopenhaners sämtliche Werke. Hrsg. von Paul Deussen. Munique: R. Piper, 1911-1942.

SCHOPENHAUER, A. Arthur Schopenhauers handschriftlicher Nachlaß. Philosophische Vorlesungen - Metaphysik der Sitten. In: SCHOPENHAUER, A. Arthur Schopenhauers sämtliche Werke. Hrsg. von Paul Deussen. Munique: R. Piper, 1911-1942, v. 10, pp. 367-584.

SCHOPENHAUER, A. O mundo como vontade e como representação. Tomo I. Tradução, apresentação, notas e índices de Jair Barboza. São Paulo: Editora UNESP, 2005.

SCHOPENHAUER, A. A arte de ser feliz. Org. de Franco Volpi; tradução de Eduardo Brandão. São Paulo: Martins Fontes, 2008.

SCHOPENHAUER, A. A arte de conhecer a si mesmo. Org. de Franco Volpi; tradução de Jair Barboza e Silvana Cabucci Leite. São Paulo: Martins Fontes, 2009.

SCHOPENHAUER, A. Aforismos para a sabedoria de vida. Tradução de Gabriel Valladão Silva. Porto Alegre: L\&PM, 2014.

VIESENTEINER, J. "Prudentia" e o uso prático da razão em Schopenhauer. Voluntas: Estudos sobre Schopenhauer, Rio de Janeiro, v. 3, n. 1 e 2, $1^{\circ}$ e $2^{\circ}$ sems. 2012, pp. 3-19.

VOLPI, F. Apresentação. In: SCHOPENHAUER, A. A arte de ser feliz: Org. de Franco Volpi; trad. Eduardo Brandão. São Paulo: Martins Fontes, 2008.

Recebido: $12 / 03 / 18$

Received: $03 / 12 / 18$

Aprovado: 21/05/18

Approved: 05/21/18 